\title{
PRZESTRZENIE TELEWIZJI - PRZESTRZENIE W TELEWIZJI - PRZESTRZENIE TELEWIZYJNE. SERIALOWE PRAKTYKI UDOMAWIANIA PRZESTRZENI
}

Alicja KISIELEWSKA

\author{
Instytut Studiów Kulturowych UwB \\ Institute of Cultural Studies, University of Bialystok \\ a.ksielewska@uwb.edu.pl \\ ORCID: 0000-0001-8295-0541
}

Telewizja, w wielorakich swoich formach, tworzy wszechobecne środowisko komunikacyjne, które stało się niejako naturalnym otoczeniem człowieka współczesnego, rodzajem ekosystemu. Możemy więc mówić o telewizyjnej mediatyzacji świata życia codziennego w Polsce. Nick Couldry i Andreas Hepp przekonująco argumentują, że żyjemy w zmediatyzowanym świecie społecznym, który jest bardzo złożony, ponieważ źródłem wielu jego form i wzorców są media i ich infrastruktura. Ich zdaniem, nawet jeśli w różnych działaniach nie korzystamy bezpośrednio z mediów, „horyzontem naszych praktyk” jest świat społeczny, dla którego są one „podstawowymi punktami odniesienia i zasobami"'.

Przedmiotem refleksji w niniejszym artykule są telewizyjne praktyki produkcji przestrzeni charakterystyczne dla telewizji naziemnej w Polsce, stanowiącej wciąż najpopularniejsze medium w naszym kraju, postrzegane $\mathrm{z}$ antropologicznej perspektywy. Kreowane w telewizji wspólnoty przestrzenne jako „wspólnoty wyobraźni” oparte są na grze przestrzenią, na wyobrażeniach przestrzennych: „tutaj”, „tam”, „nigdzie”, „wszędzie”, „u siebie”, „w domu”2. Michael Herzfeld zauważa, że „media [telewizja - przyp. A.K.] tworzą przestrzeń, w której dochodzi do gry wyobraźni i konstruowania

1 N. Couldry, A. Hepp, The Mediated Construction of Reality, Cambridge 2017, s. 15 .

2 M. Herzfeld, Antropologia, Praktykowanie teorii w kulturze i społeczeństwie, tłum. M.M. Piechaczek, Kraków 2004, s. 406. 
tożsamości”3. Na wstępie postaram się zdefiniować, jak rozumiem charakterystyczne dla telewizji praktyki produkcji przestrzeni, takie jak przestrzenie telewizji - przestrzenie w telewizji - przestrzenie telewizyjne, stanowiące podstawę telewizyjnych wspólnot wyobraźni. Przestrzenie telewizji są to różne praktyki przestrzenne organizowane przez telewizję, takie jak obecność programów telewizyjnych w domach odbiorców, ale też związane z kontekstem digitalnym i przemieszczającą się telewizją, np. noszenie obrazu ze sobą w postaci urządzeń mobilnych, wchodzenie obrazu w przestrzeń świata fizycznego - telewizje systemu 3, 4, 5D, a także wykorzystywanie przestrzeni Internetu w praktykach telewizyjnych ${ }^{4}$. Z kolei pr ze st r zen i e w telewizji stanowią obecne na ekranach przestrzenie i miejsca fizyczne, realne, przedstawiane w telewizji. Przez pojęcie przestrzenie telewizyjne rozumiem kreowane poprzez telewizyjne narracje przestrzenie wyobrażone stanowiące symboliczny system wyrażania rzeczywistości. Tworzą one symboliczne środowiska modelowane przez telewizję.

Przestrzenne ramy przedstawień medialnych, powstałych dzięki opisanym powyżej praktykom organizowanym przez telewizję, to nie tylko szczególny wymiar fizyczno-medialnej rzeczywistości, ale też rodzaj relacji międzyludzkich zapośredniczonych przez technikę telewizyjną. Wyobrażenia kreowane przez telewizję naziemną trafiają jednocześnie do milionów widzów w Polsce, a dzięki serialnej powtarzalności znaczenia, jakie one niosą, stają się niejako „naturalnymi kodami” wykorzystywanymi w praktyce przez odbiorców, tym samym przyczyniając się do mediatyzacji ich doświadczeń ${ }^{5}$. A zatem tworząc „wspólnoty wyobraźni”, telewizja kształtuje świadomość zbiorową polskiego społeczeństwa. Przedmiotem szczególnej uwagi w niniejszym artykule są telewizyjne praktyki produkcji przestrzeni w najpopularniejszych polskich obyczajowych serialach telewizyjnych produkowanych od 1997 roku przez cztery główne stacje telewizyjne:

3 Ibidem, s. 417.

4 Zob. K. Banaszkiewicz, Audiowizualność i mimetyki przestrzeni. Media, narracja, człowiek, Warszawa 2011, s. 18.

5 T. Edensor, Tożsamość narodowa, kultura popularna i życie codzienne, tłum. A. Sadza, Kraków 2004, s. 181. 
TVP1, TVP2, Polsat, TVN6. Skoncentruję się na serialach, których zrealizowano minimum dwie serie, niebędących międzynarodowymi formatami ani serialami środowiskowymi. W związku z tym, że przedmiotem refleksji są praktyki medialne i kulturowe pozwalające przyjrzeć się serialowym przestrzeniom i miejscom identyfikacyjnym Polaków w perspektywie kulturowego długiego trwania, od czasu przeobrażeń społeczno-politycznych, materiał badawczy stanowią różne odmiany gatunkowe seriali. Istotną grupą seriali poddanych analizie są polskie telesagi rodzinne, takie jak: Klan, M jak miłość, Złotopolscy, stanowiące charakterystyczny dla telewizji publicznej gatunek skoncentrowany na historii życia serialowych rodzin? ${ }^{7}$. W innych badanych serialach reguły gatunkowe nie są tak czytelne. Zdaniem Wiesława Godzica mamy do czynienia z kryzysem pojęcia gatunku jako jednoznacznie sformułowanego wzoru, rodzaju recepty czy przepisu, który widz może wykorzystać do wyprodukowania znaczenia danego tekstu telewizyjnego $^{8}$. W Polsce seriale posiadające cechy oper mydlanych określane są jako seriale obyczajowe lub telenowele. Przy czym należy zaznaczyć, że gatunki są coraz bardziej efemeryczne i nieczyste, więc wspomniane

6 TVP: Klan (od 1997, 20 serii), TVP1; Złotopolscy (1997-2010, 14 serii), TVP2; M jak miłość (od 2000, 18 serii), TVP1; Plebania (2000-2012, 12 serii), TVP1; Ranczo (2006-2016, 10 serii), TVP1; Barwy szczęścia (od 2007, 11 serii), TVP2; Londyńczycy (2008-2009, 2 serie), TVP1; Blondynka (od 2010, 5 serii), TVP1; Dziewczyny ze Lwowa (2015, 2017; 2 serie), TVP1; Leśniczówka (od 2018, 3 serie) TVP1; Za marzenia (od 2018, 2 serie), TVP2. Polsat: Samo życie (2002-2010, 9 serii); Pierwsza miłość (od 2004, 23 serie); Hotel 52 (2010-2013, 7 serii); Przyjaciółki (od 2012, 9 serii). TVN: Magda M. (2005-2007, 4 serie); Przepis na życie (2011-2013, 5 serii); Druga szansa (2016-2018, 5 serii).

7 Teorię gatunku polskiej telesagi rodzinnej przedstawiłam w książce: Polskie telesagi - mitologie rodzinności, Kraków 2009. Wykazałam w niej, że pewne cechy formalne telesagi są zapożyczone z opery mydlanej czy telenoweli. Zgodnie z przyjętym modelem kulturowej analizy gatunkowej polska telesaga rodzinna stanowi system porozumiewania się służący tworzeniu wspólnoty interpretacyjnej, której formuła ustawicznie weryfikuje się w ekranowym trwaniu; zob. J. Mittel, A Cultural Approach to Television Genre Theory, [w:] The Television Studies Reader, eds. R.C. Allen, A. Hill, London-New York 2004, s 173. Stosuję w niniejszym tekście pisownię łączną w słowie telesaga, ponieważ weszło ono już w powszechny obieg.

8 W. Godzic, Telewizja i jej gatunki po „Wielkim Bracie”, Kraków 2004, s. 260. 
kategorie zazwyczaj nakładają się na siebie ${ }^{9}$. W związku z tym, że materiał analityczny jest ogromny, z konieczności w poszukiwaniu prawidłowości muszę posłużyć się pewnymi uogólnieniami, zapewne zacierającymi wiele zróżnicowań i charakterystycznych dla danych seriali elementów.

Zakładam, że dzięki telewizyjnym praktykom kreowania przestrzeni następuje udomawianie przestrzeni realnych-wyobrażonych widzów, zaprzeczające idei powszechnej w kulturze ponowoczesnej delokalizacji. Pytanie o sposoby organizowania przestrzeni w serialach pozwoli mi zastanowić się nad praktykami zakotwiczania odbiorców w przestrzeniach i miejscach, zarówno realnych, jak i wyobrażonych, a tym samym kształtowania polskiego zmediatyzowanego krajobrazu kulturowego. Tworzone w telewizji przestrzenie dzięki pracy wyobraźni widzów mogą być źródłem konstruowanych przez nich tożsamości, sposobem praktykowania siebie ${ }^{10}$. Spróbuję zastanowić się, w jaki sposób publiczność podróżuje przez serialowe krajobrazy w poszukiwaniu bliskich sobie przestrzeni i miejsc ${ }^{11}$. Przyjrzę się nadawaniu statusu domu przestrzeniom i miejscom pokazywanym w polskich serialach. Przy czym pojmuję dom bardzo szeroko - jako ojczyznę ideologiczną, która stanowi obraz terytorium kraju internalizowany przez Polaków w procesie socjalizacji. Wiąże się ona z tożsamością zbiorową polskiego społeczeństwa, która ma charakter unifikujący, w pewnym sensie oficjalny i może być uważana za obiektywną ${ }^{12}$. Udomawianie przestrzeni w polskich serialach telewizyjnych dokonuje się poprzez nieustanny proces przekształcania przestrzeni w miejsca i miejsc w przestrzenie, przy czym terminologiczny podział na miejsce i przestrzeń jest nieostry. Przyjmuję za Michelem de Certeau, że „miejscem jest porządek (jakikolwiek) decydu-

${ }^{9}$ O problemach genologicznych związanych z przenikaniem się kategorii gatunkowych: serial tradycyjny, telenowela, opera mydlana pisali m.in.: J. Uszyński, Telewizyjny pejzaż genologiczny, Warszawa 2004, s. 68-71; M. Niemojewski, Wizerunek rodziny w polskich telenowelach, [w:] Polskie seriale telewizyjne 2005, red. J. Uszyński, Warszawa 2005, s. 34-35; P. Nowicki, Co to jest telenowela, Warszawa 2006, s. 41.

${ }_{10}$ M. Herzfeld, op. cit., s. 417.

${ }^{11}$ A. Hill, Media Experiences. Engaging with Drama and Reality Television, Routledge, New York 2019, s. 191.

12 S. Ossowski, Analiza socjologiczna pojęcia ojczyzny, „Myśl Współczesna” 2006, nr 2, s. 162. 
jący o rozmieszczeniu elementów w stosunkach współistnienia"13. Miejsce, zdaniem autora, charakteryzuje się stabilnością, natomiast „przestrzenią jest skutek wytworzony przez działania nadające jej kierunek, szczegółowo ją opisujące, wprowadzające w wymiar czasowy oraz pozwalające jej zaistnieć jako wielofunkcyjnej jedności sprzecznych programów albo umownych więzi”. Mówiąc inaczej, „przestrzeń jest praktykowanym miejscem" ${ }^{\prime 14}$. W omawianych serialach wspólnoty przestrzenne są definiowane przez przedmioty, które określają miejsca i poprzez działania, codzienne praktyki, które określają „przestrzenie” za pomocą czynności bohaterów. Ruch jest warunkiem wytwarzania przestrzeni i łączy ją z historią ${ }^{15}$.

Seriale pojmuję tutaj jako opowieści przestrzenne tworzone zarówno przez praktyki przestrzenne samej telewizji, jak i przestrzenie i miejsca obecne na ekranie oraz przestrzenie wyobrażone, wykreowane $\mathrm{w}$ serialowych narracjach. Przedmiotem refleksji będą telewizyjne strategie przestrzenno-obrazowe.

\section{UMIEJSCAWIANIE PRZESTRZENI}

Praktyka produkcji przestrzeni $\mathrm{w}$ polskich serialach obyczajowych XXI wieku, jaką jest umiejscawianie przestrzeni realnych poprzez wybór określonych miejsc w nich pokazywanych i sposób ich przedstawiania, związana jest $\mathrm{z}$ konwencjami gatunkowymi. Krajobraz w omawianych serialach, zarówno naturalny, jak i kulturowy, podobnie jak w wielu filmach i serialach produkowanych w innych krajach, występuje w dwóch wariantach: miejskim i wiejskim; jednak wyraźnie dominują w nich przestrzenie miejskie, a właściwie wielkomiejskie. Serialowy krajobraz tworzony jest przede wszystkim przez jedno miasto: Warszawę, gdzie rozgrywa się akcja większości seriali, zarówno produkcji TVP (Klan, Złotopolscy, M jak miłość, Barwy szczęścia, Dziewczyny ze Lwowa), jak i Polsatu (Samo Życie, Hotel 52, Przyjaciótki) oraz TVN (Magda M, Przepis na życie, Druga szansa). W tych

13 „Miejsce jest więc tymczasową konfiguracją położeń. Implikuje wskazywanie stabilności”. Zob. M. de Certeau, Wynaleźć codzienność. Sztuki działania, tłum. K. Thiel-Jańczuk, Kraków 2008, s. 117.

14 „W odróżnieniu od miejsca, przestrzeń jest pozbawiona jednoznaczności oraz stabilności »własnego «". Zob. M. de Certeau, op. cit., s. 117.

15 Ibidem, s. 118. 
ostatnich Polska prowincjonalna nie istnieje. Inne znaczące przestrzenie miejskie występują w serialach sporadycznie. Przykładem może być serial Dziewczyny ze Lwowa, którego akcja częściowo rozgrywa się we Lwowie, przy czym sceny te kręcone były w Przemyślu. Wyjątki stanowią: serial Polsatu Pierwsza miłość, którego akcja rozgrywa się we Wrocławiu, oraz serial TVP Londyńczycy, realizowany w Londynie, Katowicach i Łodzi.

Przedstawiany w serialach krajobraz Warszawy tworzą znane, wręcz emblematyczne dla stolicy obiekty i miejsca, takie jak: Pałac Kultury i Nauki, Zamek Królewski, Krakowskie Przedmieście, ale też nowoczesna architektura, którą symbolizują zbudowane ze stali i szkła drapacze chmur. Warszawa kreowana w serialach ma wielkomiejski, kosmopolityczny charakter, jest miastem, którego architektura odpowiada dynamice życia bohaterów. Serialowy polski wielkomiejski - czytaj najczęściej warszawski krajobraz ma się kojarzyć z cywilizacyjną modernizacją związaną z procesami globalizacyjnymi. Występuje on najczęściej w serialach obyczajowych, takich jak: Dziewczyny ze Lwowa, Przyjaciótki, Magda M., Przepis na życie służąc zlokalizowaniu przez widzów miejsca akcji. Akcja telesag zwykle toczy się w przestrzeniach zamkniętych - najczęściej jest to dom lub miejsca funkcjonujące jak dom. Jednak obraz Warszawy w serialach tworzą nie tylko miejsca realne, identyfikacyjne dla wszystkich Polaków, ale także - a może przede wszystkim - wykreowane serialowe miejsca znaczące, np.: dom na ulicy Deszczowej, w którym mieszkają Kinga i Piotr Zduńscy, bohaterowie M jak miłość, willa na Sadybie w serialu Klan, kamienica na starej Pradze, w której znajduje się mieszkanie wynajmowane przez bohaterki serialu Dziewczyny ze Lwowa, osiedle Pod Sosnami na ulicy Zacisznej w Barwach szczęścia, salon fryzjerski jednej z bohaterek Przyjaciółek czy kancelaria adwokacka, w której pracuje Magda M. Coraz częściej udomowionymi miejscami znaczącymi w życiu bohaterów omawianych seriali stają się ich miejsca pracy znajdujące się w publicznej przestrzeni wielkomiejskiej. Przykładem może być pokazywana jako miejsce przyjazne, wręcz rodzinne, restauracja „Przepis”, której właścicielką jest Anka, główna bohaterka serialu Przepis na życie. Podkreśla to scenografia restauracyjnej kuchni, która przypomina kuchnię w mieszkaniu bohaterki. Dotyczy to ciepłego koloru ścian, sposobu pokazania kuchennych akcesoriów, m.in. stojących na półkach słoików i butelek z kolorowymi płynami. Wystrój kuchni dopełniają kwiaty i leżące na stołach warzywa. W sali restauracyjnej znajdują się duże 
stoły przykryte obrusami w czerwono-białą kratkę i białe krzesła tworzące rodzinny klimat, a przed wejściem do restauracji ustawione są małe stoliki $i$ kolorowe leżaki. Podobnie wyjątkowe, rodzinne serialowe miejsce stanowi prowadzone przez Kingę Zduńską „Bistro za rogiem” przypominające z zewnątrz letniskowy domek, wokół którego znajduje się dużo kwiatów. Wystrój bistro jest wręcz domowy, ponieważ w środku widzimy dużo ocieplających przestrzeń elementów, takich jak: regały z książkami, wiszące na ścianach obrazy, lampki nocne - wszystko w żywych, ciepłych barwach. Bistro może kojarzyć się widzom M jak miłość z domem Mostowiaków w Grabinie, który dla pokolenia zadomowionych w nim przez lata nadawania serialu odbiorców był ich drugim, wyobrażonym domem ${ }^{16}$. Owo udomawianie miejsc w omawianych serialach za pomocą elementów scenograficznych polega na stosowaniu znanego kodu filmowego służącego charakteryzowaniu miejsca akcji ${ }^{17}$. Natomiast zjawisko serialowego udomawiania miejsc, jakimi są np. restauracje, wynika z mody na „domowość”, jaką obserwujemy w wystroju wielu kawiarni i restauracji w naszym kraju. Być może stanowi ona wyraz kulturowej potrzeby tworzenia w przestrzeni publicznej miejsc charakteryzujących się rodzinno-domową atmosferą.

Opozycją wobec kosmopolitycznych wielkomiejskich klimatów Warszawy w polskich serialach jest prowincjonalność małych miasteczek, na ogół fikcyjnych, takich jak Gródek (M jak miłość), Hrubielów (Plebania), lub wsi, również fikcyjnych: Grabina (M jak miłość), Tulczyn (Plebania), Majaki (Blondynka), Wadlewo (Pierwsza miłość). Polskie prowincjonalne krajobrazy, które występują niemal wyłącznie w produkcjach TVP, z jednym wyjątkiem polsatowskiej Pierwszej miłości, stanowią swojskie terytoria przeciwstawione obcemu, nieznanemu światu - przestrzeń, która zapewnia bohaterom, ale też widzom, poczucie bezpieczeństwa. Obraz prowincji przedstawiany jest w serialach w konwencji lekko wykpiwanej sielanki, polegającej na osobliwym kulcie prowincjonalności związanym $\mathrm{z}$ terytorialnym zakorzenieniem. Jej pochwała łączy się najczęściej z wiejskim, swojskim krajobrazem:

16 Średnia oglądalność M jak miłość w sezonie 2018/2019 wyniosła 5,32 mln widzów; cyt. za: https://www.wirtualnemedia.pl/artykul/ogladalnosc-m-jak-milosc-serial-tvp2-znokautowala-konkurencje [dostęp 1.02.2020].

${ }_{17}$ M. Przylipiak, Kino stylu zerowego. $Z$ zagadnień estetyki filmu fabularnego, Gdańsk 1994, s. 50-51. 
mazowieckimi polami, lasami, łąkami (Złotopolice, Grabina) lub podlaską malowniczą szachownicą pól i doliną rzeki (Wilkowyje, Majaki). Oparta na tradycji miejsca kultura chłopska, której podstawę powinien stanowić emocjonalny związek bohaterów z lokalną wspólnotą doświadczeń, w nich nie istnieje ${ }^{18}$. W omawianych serialach, nawet jeśli ich akcja dzieje się na wsi, bohaterowie nie pracują na roli. Natomiast postaci wywodzące się ze środowiska wiejskiego, takie jak: listonosz Józef, kelnerka Marcysia, Pereszczako ze Złotopolskich czy Bazyli Dalmata, Auguścikowa, babka zielarka z Rancza, są traktowane z ciepłą ironią. Wykreowane w serialach udomawiane miejsca znaczące w przestrzeni prowincjonalnej, w których usytuowani są bohaterowie, stanowią najczęściej idealne ich wyobrażenia widziane z perspektywy producentów, ponieważ niewiele mają one wspólnego z realiami ludzi w nich żyjących. Zwrócę uwagę jedynie na kilka egzemplarycznych przestrzeni. Wyjątkowym miejscem występującym we wszystkich serialach, których akcja dzieje się na prowincji (Złotopolscy, Plebania, Ranczo, Blondynka, Leśniczówka), jest budynek katolickiego kościoła, zazwyczaj stary, często drewniany. Pokazywany jest on jako miejsce kultu religijnego, ale przede wszystkim jako centrum wiejskiej wspólnoty, ponieważ częściej odbywają się w nim rozmowy parafian z księdzem niż liturgia. Podobne wspólnotowe funkcje pełni w serialach katolicka plebania (Ranczo, Plebania), w której często przy stole w otoczeniu wiszących na ścianach krzyży i zdjęć Jana Pawła II - koncentruje się życie parafii. Na jej lokalne zakorzenienie i trwanie wiejskiej tradycji wskazują przedmioty codziennego użytku, np. w kuchni na plebanii w Tulczynie (Plebania) możemy zobaczyć tradycyjną płytę kuchenną i wiejskie makatki. Charakterystycznym punktem na serialowej mapie prowincji jest także wiejski sklep, którego stereotypowo pokazywane wyposażenie kojarzy się z czasami PRL (Złotopolscy, Ranczo).

Miejscem identyfikacyjno-tożsamościowym, które najpełniej wyraża ideę polskiego krajobrazu, zarówno w wydaniu wielkomiejskim, jak i prowincjonalnym, w omawianych serialach, w sensie architektury i ideału kulturowego, jest dom. Wersje „polskiego domu”, przedstawione w serialach, są przeróżne, ale najczęściej występuje on w formie nawiązującej do szlacheckiego dworku uchodzącego za jego tradycyjny kulturowy ideał.

18 Zob. W. Myśliwski, Kres kultury chłopskiej, Warszawa 2003. 
W epoce rozbiorów dwór ziemiański, jego forma i charakter stanowiły rodzaj manifestacji polskości i rodzimości. W pierwszej połowie XIX wieku ukształtował się wzorzec polskiego dworku także jako forma oporu wobec kosmopolitycznych trendów w architekturze - parterowy, zbudowany symetrycznie wokół osi, w stylu klasycystycznym ${ }^{19}$. Dom polski w serialach najczęściej stanowią uwspółcześnione wersje dworku. Najpełniej w ten wzór wpisuje się tradycyjny dworek w Złotopolicach w serialu Złotopolscy, ale w stylu „dworkowym”, będącym wyrazem architektonicznej mody na dworki w ostatnich dziesięcioleciach w Polsce, mieszczą się też: willa na warszawskiej Sadybie w Klanie, dom z obowiązkowym przy dworku sadem w Grabinie w M jak miłość, dworek Amerykanki Lucy w Wilkowyjach w Ranczu, dom profesora muzyki w Warszawie w Dziewczynach ze Lwowa, w salonie którego, zgodnie z dworkowym stylem, znajdują się stare meble, kominek, obrazy na ścianach, biblioteczka z książkami. Podobny wystrój ma zatopiony w zieleni rodzinny dom Marysi z Pierwszej miłości w Wadlewie.

Stosunkowo nowym serialowym wzorem, jeśli chodzi o ideę „domu polskiego”, może być mieszczańskie mieszkanie pani Nowakowej w Warszawie w serialu Dziewczyny ze Lwowa, pełne starych, stylowych mebli, kryształów, bibelotów i obrazów na ścianach. Wzór ten w serialach, jak się wydaje, zastąpił eksponowany w czasach PRL ideał „inteligenckiego” mieszkania w bloku. W serialu Samo życie mieszkanie, w którym charakterystycznymi elementami są biblioteka, biurko, komputer, ma dziennikarka Elżbieta i jej mąż, dyrektor liceum. Na koniec jedna wątpliwość: czy mieszkanie bohaterki Drugiej szansy w apartamentowcu o zimnej stechnicyzowanej nowoczesnej architekturze, w której dominuje stal i szkło, może być uznane za „dom polski"?

$\mathrm{W}$ analizowanych serialach wyjątkowym przedmiotem w serialowej fabule, kreującym tradycyjne wyobrażenie domu jako specyficznego miejsca, jest okrągły stół. W XIX wieku na ziemiach polskich stoły jadalne nazywano stołami rodzinnymi ${ }^{20}$. W okresie zaborów okrągły stół zyskiwał szczególne znaczenie, nie tylko ceremonialno-biesiadne, ale też jako symbol tożsamościowy. Okrągły stół występuje w wielu serialowych domach i na

19 D. Kałwa, Polska doby rozbiorów i międzywojenna, [w:] Obyczaje w Polsce. Od średniowiecza do czasów współczesnych, red. A. Chwalba, Warszawa 2006, s. 250-251.

20 I. Grzeluk, Słownik terminologiczny mebli, PWN, Warszawa 2000, s. 183-184. 
ogół symbolizuje wspólnotę rodzinną oznaczającą udomowienie. W polskich telesagach rodzinnych zwykle stoi on w salonie (Klan, M jak miłość, Złotopolscy), gdzie spotykają się domownicy, ale też czasami w kuchni, np. w mieszkaniu Pawła Zduńskiego (M jak miłość). Znajduje się on także w serialu Plebania w domu księdza Henia i matki Kasi oraz na plebanii, jak również na plebanii w serialu Ranczo. Natomiast w Dziewczynach ze Lwowa okrągły stół jest charakterystycznym przedmiotem w mieszkaniach, które sprzątają bohaterki, np. w domu profesora muzyki, gdzie zwykle nakrywa się go do obiadu białym obrusem i stawia się na nim porcelanową zastawę. Możemy go zobaczyć również w wynajmowanym przez bohaterki od pana Henryka skromnym mieszkaniu w starej kamienicy na warszawskiej Pradze. Okrągły stół przykryty obrusem wydzierganym na szydełku stoi w wyposażonym w stare meble pokoju głównej bohaterki Blondynki we wsi Majaki, a także w salonie domu rodzinnego głównej bohaterki serialu Pierwsza miłość w Wadlewie. Nad drzwiami salonu wisi krzyż, poza tym stoi w nim stara szafa gdańska, a na ścianach wiszą fotografie rodzinne. W serialu Hotel 52, którego akcja dzieje się w Warszawie, w salonie Igora i jego ojca również został umieszczony okrągły stół. Z przytoczonych przykładów wynika, że okrągły stół jest symbolem trwania, zakorzenienia, udomawiania różnych przestrzeni.

W omawianych serialach pokazywane są także miejsca, z którymi Polacy, jak zakładają twórcy, nie chcieliby się identyfikować, np.: „domy polskie” wykpiwane, jak nowobogacka willa gangstera w Warszawie w Dziewczynach ze Lwowa, podobny w stylu dom należący do miejscowego kamieniarza, fana Arnolda Schwarzeneggera, w Majakach w Blondynce, ogromny kiczowaty dom wójta w Wilkowyjach w serialu Ranczo. Należą do nich także te, do których Polacy nie chcieliby się przyznawać, np. domy ubogich mieszkańców Wilkowyj w Ranczu. Z tych samych powodów bardzo rzadko pokazywane są w serialach charakterystyczne dla polskich miast przestrzenie blokowisk, w których żyją miliony Polaków. Jednym z wyjątków może być koszmarna rzeczywistość blokowiska w Katowicach, do którego wraca Andrzej, jeden z bohaterów Londyńczyków. Perspektywa życia w szarym, odrapanym bloku z wielkiej płyty, w ciasnym i zagraconym mieszkaniu zajmowanym przez matkę, siostrę w ciąży i jej partnera, powoduje, że bardzo szybko wraca on do Londynu. 


\section{PRZEKSZTALCANIE MIEJSC W PRZESTRZENIE}

Serialowa praktyka udomawiania dotycząca kreacji „domu polskiego” jako symbolicznej rodzinno-domowej wspólnoty wyobrażonej, do której twórcy seriali zapraszają widzów, następuje poprzez działania bohaterów. W analizowanych serialach dom rozumiany jako wspólnota nie jest statyczny, ulega ciągłemu reprodukowaniu poprzez prace domowe oraz działania społeczne i kulturowe tworzące narodowe konstrukcje „my” - „oni”, poprzez włączanie lub wykluczanie ${ }^{21}$. Dotyczy to serialowych przestrzeni wielkomiejskich, ale przede wszystkim przestrzeni prowincjonalnych. W sercu często pokazywanego tradycyjnego „domu polskiego" w serialach sytuuje się kuchnia, która nie jest jedynie miejscem spożywania posiłków, lecz stanowi centrum życia rodzinnego. Jeśli szukalibyśmy szerszego odniesienia w perspektywie historyczno-kulturowej, to warto zaznaczyć, że w XIX wieku funkcję miejsca wspólnego rodziny, a zarazem reprezentacyjnego, w bogatych domach, dworach i pałacach pełniły salon i jadalnia. Natomiast najważniejszym pomieszczeniem w domu chłopskim, gdzie toczyło się życie rodziny, była izba kuchenna ${ }^{22}$. Polski sposób bycia w kuchni w serialach to m.in. domowe praktyki gotowania i rozmowy przy posiłkach. Ten typ domowej rodzinności występuje przede wszystkim w serialach TVP: Klanie, $M$ jak miłość, Złotopolskich, Plebanii, Ranczu, Londyńczykach, Dziewczynach ze Lwowa, ale też w serialu Polsatu Barwy szczęścia. W kuchni domu w Grabinie, w najpopularniejszym polskim serialu M jak miłość, toczy się życie rodzinne i towarzyskie, którego charakterystyczną cechą, zgodnie z konwencją telesagi, są rozmowy przy stole, ale przyjmuje się tam również gości, zarówno tych zaproszonych, jak i niespodziewanych, którzy zgodnie z tradycyjna polską normą gościnności są częstowani jedzeniem ${ }^{23}$. Podobne funkcje pełni kuchnia w mieszkaniu pani Janiny w serialu Samo życie znajdującym się

${ }^{21}$ T. Edensor, op. cit., s. 84-85.

22 D. Kałwa, op. cit., s. 256-258.

${ }^{23}$ Podobne sceny przedstawiające domowe praktyki gotowania i rozmowy przy stole w czasie wspólnie spożywanych posiłków przez wielopokoleniowe rodziny występują też w niemieckich czy austriackich serialach familijnych. Niedawno w telewizji polskiej można było oglądać takie seriale, jak Doktor z alpejskiej wioski czy Doktor Kleist. Sytuują się one w tradycji niemieckich, austriackich i szwajcarskich Heimatfilmów, a także seriali. 
w warszawskiej kamienicy. Najczęściej w kuchni toczą się również rozmowy w nowocześnie, dizajnersko urządzonych i dobrze wyposażonych mieszkaniach w blokach na jednej z warszawskich ulic w Barwach szczęścia, ponieważ jest to charakterystyczne dla polskiej praktyki kulturowej, po części wynikającej z architektury polskich domów i mieszkań. Bohaterka Przepisu na życie wprawdzie gotuje rodzinie, ponieważ lubi to robić, a gotowanie stanowi jej pasję i zawód, ale kuchnia nie stanowi w jej domu centrum życia rodzinnego. W dużej mierze zostało ono przeniesione do restauracji pełniącej pewne funkcje domu, ponieważ pracujące w niej osoby tworzą rodzaj wspólnoty przypominającej rodzinę. Idea tradycyjnego „domu polskiego” jako przestrzeni wyobrażonej określającej rodzaj wspólnoty w serialach TVN nie występuje.

Inną wersją „domu polskiego" pokazywanego w serialach, którego idea pomimo procesów migracyjnych wciąż trwa, może być „dom polski” na obczyźnie - rodzaj miejsca własnego powstałego poprzez oswajanie obcej przestrzeni społecznej. Przykładem może być „dom polski” Pani Niny $\mathrm{w}$ Londynie w polskiej dzielnicy Ealing w serialu Londyńczycy. To jednak nie architektura (w tym przypadku wiktoriańska) ani wyposażenie domu (np. stojące w kuchni na regałach naczynia z Włocławka czy stare eleganckie meble w salonie) są tutaj znaczące. Przestrzeń jest tu bowiem systemem symbolicznym, umożliwiającym porządkowanie świata w kategoriach swojskości i obcości ${ }^{24}$. Bohaterowie serialu, młodzi polscy emigranci, znajdują w domu Pani Niny schronienie, a odtwarzanie przez nich „małej ojczyzny” na emigracji ma wymiar przede wszystkim rodzinny. W Londyńczykach budowanie „domu polskiego” oparte jest na ciągłych wyborach: swój - obcy, inkluzja - ekskluzja. Pewnym wyznacznikiem dokonującego się procesu udomawiania w sytuacji pluralizmu kulturowego Londynu są goście, których, zgodnie z polską normą, zaprasza się do domu. W serialu, oprócz Polaków, są nimi Brazylijczycy i Anglicy. W Londyńczykach możemy też zobaczyć, że tożsamość narodowa i poczucie domu mogą być jednocześnie zakorzenione i mobilne. Para bohaterów, Paweł i Maria, to Europejczycy, którzy przede wszystkim czują się Polakami i pomimo sukcesów zawodowych i ekonomicznych w Londynie wracają do kraju, aby tutaj żyć i pracować.

24 Zob. E. Nowicka, Swoi i obcy, red. E. Nowicka i in., Warszawa 1990, s. 5-53. 
Przyjeżdżają do rodzinnego miasta Pawła - Łodzi, której nowoczesna architektura pokazana w serialu jest podobnie atrakcyjna, jak ta w Londynie. Problem domu jednak istnieje. Po ich powrocie matka Pawła mówi do Marii, że „każdy powinien wiedzieć, kim jest i gdzie jest jego miejsce”25.

Przedstawiłam w tym artykule jedynie najbardziej charakterystyczne telewizyjne praktyki udomawiania przestrzeni w serialach. Wykreowane w nich wspólnoty oparte są na wyobrażeniach przestrzennych: „tutaj”, „u siebie”, „w domu" i mają charakter raczej lokalny - polski niż globalny ${ }^{26}$. Dotyczy to zarówno polskich telesag rodzinnych, co wydaje się dosyć oczywiste, ale też innych seriali. Przy czym są to nowego rodzaju przestrzenne wspólnoty lokalne czy raczej translokalne stanowiące rodzaj wyobrażonej lokalności zmediatyzowanej ${ }^{27}$. Możemy mówić o stapianiu się w nich przestrzeni realnych, fizycznych i medialnych, charakterystycznym dla zmediatyzowanej kultury, w jakiej żyjemy i w której coraz częściej nie sposób dokonać czytelnego podziału na „kulturę" i „kulturę mediów”28. W kreowaniu znaczenia serialowych opowieści przestrzennych istotne są także przestrzenie telewizji, czyli praktyki przestrzenne telewizji naziemnej w Polsce. Wieloekranowość i wieloformatowość telewizji w dobie post-broadcast nie spowodowały radykalnej zmiany, jeśli chodzi o zakres jej oddziaływania w naszym kraju. Dla większości naszych rodaków telewizja naziemna wciąż pozostaje medium domowo-rodzinnym oglądanym najczęściej za pomocą telewizora ${ }^{29}$. A poza tym łączy ona centrum z peryferiami i wciąż posiada zdolność tworzenia

25 Cytat pochodzi ze ścieżki dźwiękowej serialu Londyńczycy, seria 2, odcinek 12.

26 Zob. A.C. Pertierra, G. Turner, Locating Television: Zones of Consumption, Routledge, London-New York 2013, s. 6.

27 N. Couldry, A. Hepp, op. cit., s. 87.

28 W Supraślu, gdzie realizowane są zdjęcia do serialu Blondynka, funkcjonuje, będący elementem serialowej fabuły, salon fryzjersko-kosmetyczny „U Elwirki”, w którym można sobie przystrzyc włosy.

${ }^{29}$ W 2018 roku 80\% Polaków oglądało telewizję „na żywo”, czyli w czasie jej nadawania, $16 \%$ telewizję przesuniętą w czasie, $56 \%$ online wideo; $6 \%$ odpowiedziało: „Nie oglądam tv”. Cyt. za: www.wirtualnemedia.pl/artykul/ogladalnosc-telewizji2018-rok-atv-top-kanaly-programy-reklama, [dostęp 1.02.2020]. 
sensów wspólnoty wynikających z poczucia współobecności i współuczestnictwa odbiorców ${ }^{30}$. Istotnym narzędziem wspólnotowości budowanej przez telewizję naziemną w Polsce są popularne seriale, a w sposób szczególny praktyki udomawiania przestrzeni służące tworzeniu identyfikacyjnych wspólnot wyobraźni. W związku z tym udomawiane w niej przestrzenie stanowią element społecznego imaginarium ${ }^{31}$. Na podstawie przeprowadzonych analiz dochodzę do wniosku, że najbardziej charakterystyczna forma udomawiania przestrzeni w omawianych serialach, jaką stanowi tradycyjne wyobrażenie „domu polskiego” przedstawiane w serialach TVP i Polsatu, powoli odchodzi w przeszłość i jest zastępowana przez inne identyfikacyjne wspólnoty przestrzenne, np. związane z miejscami pracy. Istotne jest przy tym, aby zmediatyzowane, wyidealizowane, sztuczne przestrzenie były przyjazne i bliskie emocjonalnie odbiorcom, aby mogły się stać elementem negocjowanych przez nich za pomocą serialowych narracji ponowoczesnych tożsamości. Poza tym seriale są źródłem przyjemności widzów, więc dzięki powszechnej mediatyzacji doświadczeń każdy z nich może się poczuć jak w domu w nowej telewizyjnej lokalności.

\section{Bibliografia}

Karina Banaszkiewicz, Audiowizualność i mimetyki przestrzeni. Media, narracja, człowiek, Oficyna Naukowa, Warszawa 2011.

Nick Couldry, Andreas Hepp, The Mediated Construction of Reality, Polity Press, Cambridge 2017.

Michel De Certeau, Wynaleźć codzienność. Sztuki działania, tłum. K. Thiel-Jańczuk, Wydawnictwo UJ, Kraków 2008.

Tim Edensor, Tożsamość narodowa, kultura popularna i życie codzienne, tłum. A. Sadza, Wydawnictwo UJ, Kraków 2004.

Wiesław Godzic, Telewizja i jej gatunki po „Wielkim Bracie”, Universitas, Kraków 2004. Izydor Grzeluk, Słownik terminologiczny mebli, PWN, Warszawa 2000.

Michael Herzfeld, Antropologia. Praktykowanie teorii w kulturze i społeczeństwie, tłum. M.M. Piechaczek, Wydawnictwo UJ, Kraków 2004.

${ }^{30}$ G. Turner, Essays in Media and Cultural Studies. In Transition, London-New York 2020, s. 24.

${ }^{31}$ Ch. Taylor, Nowoczesne imaginaria społeczne, tłum. A. Puchejda, K. Szymaniak, Kraków 2010. s. 37. 
Annette Hill, Media Experiences. Engaging with Drama and Reality Television, Routledge, New York 2019.

Dorota Kałwa, Polska doby rozbiorów i międzywojenna, [w:] Obyczaje w Polsce. Od średniowiecza do czasów współczesnych, red. A. Chwalba, PWN, Warszawa 2006.

Alicja Kisielewska, Polskie telesagi - mitologie rodzinności, Rabid, Kraków 2009.

Jason Mittel, A Cultural Approach to Television Genre Theory, [w:] The Television Studies Reader, red. R.C. Allen, A. Hill, Routledge, London-New York 2004.

Wiesław Myśliwski, Kres kultury chłopskiej, Prowincjonalna Oficyna Wydawnicza, Warszawa 2003.

Marcin Niemojewski, Wizerunek rodziny w polskich telenowelach, [w:] Polskie seriale telewizyjne 2005, red. J. Uszyński, Telewizja Polska S.A., Warszawa 2005.

Ewa Nowicka, Swo i i obcy, Instytut Socjologii UW, Warszawa 1990.

Paweł Nowicki, Co to jest telenowela, Oficyna Wydawnicza ASPRA-JR, Warszawa 2006.

Stanisław Ossowski, Analiza socjologiczna pojęcia ojczyzny, „Myśl Współczesna” 2006, nr 2.

Anna Cristina Pertierra, Graeme Turner, Locating Television: Zones of Consumption, Routledge, London-New York 2013.

Mirosław Przylipiak, Kino stylu zerowego. Z zagadnień estetyki filmu fabularnego, Gdańskie Wydawnictwo Psychologiczne, Gdańsk 1994.

Charles Taylor, Nowoczesne imaginaria społeczne, tłum. A. Puchejda, K. Szymaniak, Znak, Kraków 2010.

Graeme Turner, Essays in Media and Cultural Studies. In Transition, Routledge, London-New York 2020.

Jerzy Uszyński, Telewizyjny pejzaż genologiczny, Telewizja Polska S.A., Warszawa 2004. 


\section{Television Spaces - Spaces on TV - TV Spaces. Serial Space Domestication Practices}

The subject of reflection in this article are television space production practices, such as: television spaces - spaces on TV - TV spaces in the most popular Polish drama series produced since 1997 by major broadcasting television stations. I focus on the 'communities of imagination' as spatial communities created in TV series perceived as spatial stories. I assume that thanks to the television practices of creating real-imagined space, space is being domesticated, contradicting the idea of relocation common in postmodern culture. In this article, I propose an analysis of television spatial and image strategies that are rooted in Polish culture. The spaces created on television thanks to the work of the viewers' imagination can be the source of the identities they construct, a way of practicing oneself with the participation of traditional television.

Keywords: TV spaces, Polish drama series, broadcasting television, domestication

Data otrzymania tekstu: $30.11 .2020 \mathrm{r}$.

Data zakończenia procesu recenzyjnego: 20.04.2021 r.

Data akceptacji tekstu do druku: 27.04.2021 r. 